\title{
Akurasi Pengukuran kWh Meter Analog Terhadap Losses Energi Listrik
}

\author{
Alfi Novri Waldi ${ }^{1}$; Samsurizal ${ }^{2}$ \\ 1,2Teknik Elektro, Institut Teknologi PLN, Jakarta \\ ${ }^{2}$ samsurizal@itpln.ac.id
}

\begin{abstract}
Every measurement of electrical energy has a vital and very decisive role. Kilo Watt Hour (kWh) meter is an equipment used to measure a value or price of electricity usage (watt hour) in the period of time used. The problem of losses that occur in the kWh Meter is one of the problems. The problem faced is how to make readings and measurements of the use of electricity measured properly. In this study, the objectives to be achieved are to find out when the kWh meter deviation calculation shows results of no more than the permissible $k W h$ deviation tolerance, namely $-2 \%$ and $+2 \%$ results and to correct electrical energy losses, ranging from technical and non-technical kWh meter errors. technical. Based on the results of research conducted using manual calculations and using special software. With the software makes it easier for studies to be carried out. In this case, it is the non-technical determination of $\mathrm{kWh}$ that usually accounts for the biggest losses, because this is not $100 \%$ pure damage from the kWh Meter, but there are PLN Consumers who are not responsible for the losses given. From the results of technical testing of the $3 \mathrm{kWh}$ Meter which obtained data and specifications up to the deviation of the $\mathrm{kWh}$ Meter and from the results of studies conducted on non-technical testing, it turns out that this is what contributes to losses on a large scale.
\end{abstract}

Keywords: kWh meter, Losses, Measurement, Accuracy

\begin{abstract}
ABSTRAK
Setiap pengukuran energi listrik memiliki peran yang vital dan sangat menentukan. Kilo Watt Hour (kWh) meter merupakan peralatan yang digunakan untuk dapat mengukur suatu nilai atau harga dari penggunaan listrik (watt jam) dalam kurun waktu yang digunakan. Permasalahan losses yang terjadi pada kWh Meter menjadi salah satu masalah. Permasalahan yang dihadapi bagaimana cara agar pembacaan dan pengukuran dari penggunaan listrik terukur dengan baik. Pada studi ini tujuan yang ingin dicapai adalah mengetahui saat perhitungan deviasi kWh meter menunjukkan hasil tidak lebih dari toleransi deviasi kWh yang diperbolehkan yaitu hasil -2\% dan $+2 \%$ dan untuk memperbaiki losses energi listrik, mulai dari kesalahan kWh Meter secara teknis maupun non-teknis. Berdasarkan hasil penelitian yang dilakukan menggunakan perhitungan secara manual dan menggunakan software khusus. Dengan adanya software tersebut mempermudah studi yang dilakukan. Dalam hal ini, penentuan kWh secara non-teknis lah yang biasanya menyumbang rugi-rugi paling besar, dikarenakan ini bukan 100\% murni kerusakan dari kWh Meter, melainkan ada Konsumen PLN yang tidak bertanggung jawab atas losses yang diberikan. Dari hasil pengujian secara Teknis terhadap $3 \mathrm{kWh}$ Meter yang dimana didapatkan data dan spesifikasi hingga deviasi kWh Meter dan dari hasil studi yang lakukan terhadap pengujian secara Non Teknis, tenyata hal inilah yang menyumbang losses dalam skala yang besar.
\end{abstract}

Kata kunci: kWh meter, Losses, Pengukuran, Akurasi 


\section{PENDAHULUAN}

kWh meter sendiri adalah suatu alat ukur yang melakukan transaksi energi, dalam hal ini harus disetujui oleh pelanggan dan juga perusahaan yang bersangkutan dan tentunya harus mendapat verifikasi dari pemerintahan tersebut. Dalam kesalahan pengukuran pada saat transaksi energi, hal ini dapat menyebabkan pelanggan melakukan complain terhadap perusahaan listrik yang menyediakan jasanya tersebut. Pada hakikatnya, jumlah energi listrik yang telah digunakan oleh pelanggan akan terukur dan tercatat secara langsung melalui stand meter yang ada pada alat ukur kWh meter pelanggan masing-masing. Apabila pelanggan merasa tagihan listrik yang tiba-tiba menjadi murah sedangkan pelanggan memakai energi listrik dengan selayaknya dari penggunaan bulan-bulan sebelumnya, tetapi pelanggan tidak melaporkan hal ini ke pihak perusahaan listrik tersebut, maka hal ini pelanggan dapat terkena pelanggaran yang sanksinya berupa Tagihan Susulan (TS) yang dihitung dari penggunaan energi listrik rata-rata pada bulanbulan sebelumnya.

Apabila pada kWh meter terjadi kerusakan pada komponen ataupun pelanggan yang melakukan pencurian listrik yang mengakibatkan suatu pengukuran pada kWh meter menjadi tidak normal, maka dengan hal ini dapat dikenakan sanksi P1, P2 dan P3. Untuk kasus pencurian listrik seperti melakukan penggantian $\mathrm{MCB}$ yang tidak sesuai dengan daya kontrak PLN (P1), memasang kawat/lempengan tembaga pada Terminal 1 dan 3 yang diparalel (P2), dan selanjutnya pelanggaran yang lebih parah lagi yaitu dengan cara pelanggan melakukan pencurian langsung melalui sumber kemudian menyuntikkan langsung kabel SR sehingga pada kWh meter tidak mengukur (P3). Kemudian kasus berikutnya apabila terjadi kejanggalan seperti tagihan listrik tiba-tiba menjadi murah yang berkemungkinan besar terjadi kerusakan pada komponen-komponen kWh meter namun pelanggan tidak memberi tahu permasalahan ini ke pihak PLN, dalam hal ini pelanggan dapat terkena sanksi K1/K2 yaitu suatu pelanggaran yang disebabkan oleh kelainan yang terjadi pada komponen kWh meter, maka dari hal tersebut PLN memberikan Tagihan Susulan (TS) pada pelanggan yang terkenal pelanggaran tersebut. Tagihan Susulan (TS) ini dihitung berdasarkan sesuai dengan penggunaan energi listrik rata-rata pada beberapa bulan sebelumnya.

\section{METODE PENELITIAN}

Pada hakikatnya, suatu usaha untuk melakukan proses mengukur yang menyatakan sifat dari suatu alat/komponen yang dituangkan dalam bentuk nilai baik itu angka maupun harga, itulah yang dinamakan pengukuran. Landasan kita dapat memberikan suatu angka atau harga pada saat melakukan pengukuran dengan cara alat yang akan dilakukan pengukuran dengan membandingkan alat yang sudah dinyatakan akurat dikarenakan standarisasinya diperbandingkan dengan alat yang akan kita ukur nantinya.Kilo Watt Hour $(\mathrm{kWh})$ meter adalah alat yang digunakan untuk dapat mengukur suatu nilai atau harga dari penggunaan listrik (watt jam) dalam kurun waktu yang digunakan. Jadi pada kWh meter ini sudah terpasang 1 buah disc (piringan) serta alat hitung yang biasa disebut penghitungan mekanis. Pada alat ukur ini tersusun oleh kumparan voltase yang terhubung secara parallel dengan bebannya dan pada kumparan arusnya yang terhubung secara seri dengan beban juga.

Total dari energi listrik yang dihasilkan oleh kWh meter diubah dalam bentuk energi mekanis, hal ini terjadi karena berguna untuk memutar piringan $\mathrm{kWh}$ meter dan juga counter stand meter pada kWh meter, hal ini dapat terjadi karena jumlah energi listrik yang kita gunakan dengan perputaran piringan dan juga counter pada stand meter sesuai atau masih berlaku secara normal. 


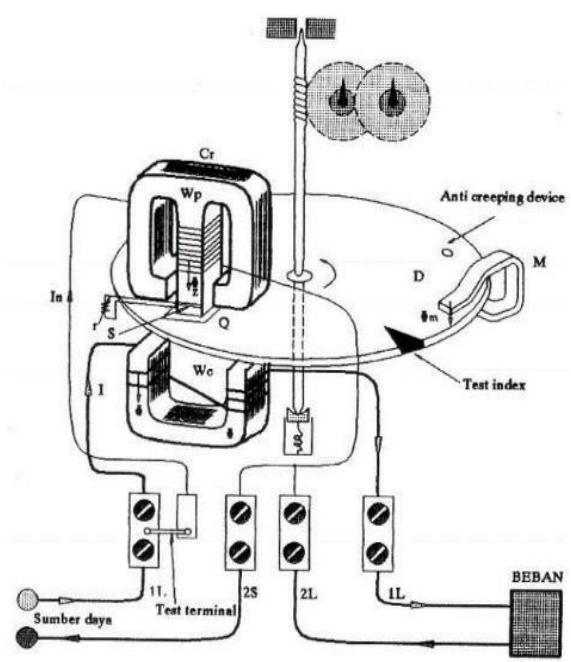

Gambar 1. Kontruksi kWh Meter Sumber: (Journal of Electric Technology)

Metode yang digunakan untuk melakukan pengujian kWh Meter ini dengan menggunakan metode pengukuran secara Teknis dan Non Teknis, kemudian alat yang digunakan sebagai penunjang studi ini ada 2, yaitu:

- Tang Ampere (Clamp Ampere)

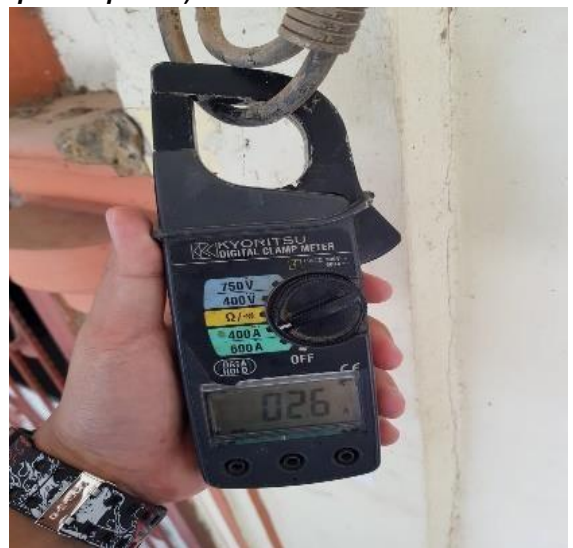

Gambar 2. Tang Ampere (Clamp Ampere)

- Tang kW

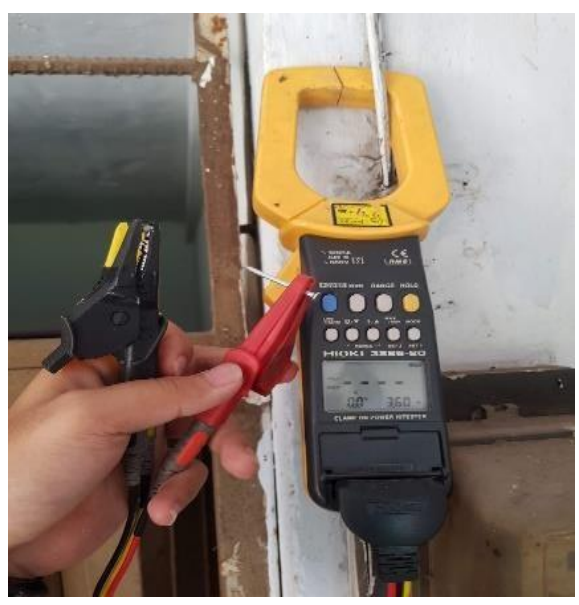

Gambar 3. Tang kW 
Teknik pengambilan sample dengan menggunakan 3 tipe kWh Meter, yaitu ada kWh Meter Melcoinda, Fuji Dharma Electric dan Sigma Electric. Variable yang diukur nantinya meliputi Daya yang terukur melewati kWh Meter, Daya aktif yang diukur melalui tang kW dan Kesalahan kWh Meter (Error \%), dimana persamaan sebagai berikut:

- Daya yang Terukur Melewati kWh Meter

$$
P 1=\frac{3600 \times n}{t \times c}
$$

Keterangan:
a) $\mathrm{P1} \quad$ = Daya yang Dihitung dari Hasil Uji (kWh Meter) Putaran Dengan Menggunakan Stopwatch/Sensor Waktu
b) $3600=$ Detik/Jam
c) $\mathrm{N} \quad$ = Banyak Putaran
d) $\mathrm{t} \quad=$ Waktu (Detik)
e) $\mathrm{C} \quad=$ Konstanta kWh Meter

- Daya Aktif yang Diukur Melalui Tang kW $\mathrm{P} 2=\mathrm{V} \times \mathrm{I} \times \operatorname{Cos} \varphi$ Keterangan:
a) P2
= Daya yang Didapatkan dari Hasil Uji (kWh Meter) Pada Tang kW
b) $\mathrm{V}$
= Tegangan (Volt)
c) 1
= Arus pada Beban (Ampere)
d) $\operatorname{Cos} \varphi=$ Faktor Daya

- Kesalahan kWh Meter (Error \%)

$$
\text { Error } \%=\frac{P 1-P 2}{P 2} \times 100 \%
$$

\begin{tabular}{|c|c|}
\hline \multicolumn{2}{|c|}{$\begin{array}{l}\text { Spesifikasi dan Nameplate kWh Meter } \\
\text { Melcoinda }\end{array}$} \\
\hline Tipe kWh Meter & MF-97E \\
\hline Pengawatan & $\begin{array}{c}\text { Fasa Tunggal } 2 \\
\text { Kawat }\end{array}$ \\
\hline Tegangan & 230 Volt \\
\hline Frekuensi & $50 \mathrm{~Hz}$ \\
\hline Konstanta & 900 Putaran/kWh \\
\hline Kelas kWh Meter & Kelas 2 \\
\hline $\begin{array}{l}\text { Batas Pengukuran kWh } \\
\text { Meter }\end{array}$ & $5(20) A$ \\
\hline Tahun kWh Meter & 2008 \\
\hline
\end{tabular}

Tabel 1. Spesifikasi dan Nameplate kWh Meter Melcoinda 
Tabel 2. Spesifikasi dan Nameplate kWh Meter Fuji Dharma Electric

\section{Spesifikasi dan Nameplate kWh Meter Fuji Dharma Electric}

\begin{tabular}{|c|c|}
\hline Tipe kWh Meter & FA14Al1Z \\
\hline Pengawatan & $\begin{array}{c}\text { Fasa Tunggal 2 } \\
\text { Kawat }\end{array}$ \\
\hline Tegangan & 230 Volt \\
\hline Frekuensi & $50 \mathrm{~Hz}$ \\
\hline Konstanta & 900 Putaran/kWh \\
\hline Kelas kWh Meter & Kelas 2 \\
\hline $\begin{array}{c}\text { Batas Pengukuran kWh } \\
\text { Meter }\end{array}$ & $5(20) \mathrm{A}$ \\
\hline Tahun kWh Meter & 2012 \\
\hline
\end{tabular}

Tabel 3. Spesifikasi dan Nameplate kWh Meter Sigma Electric

\begin{tabular}{|c|c|}
\hline \multicolumn{2}{|c|}{$\begin{array}{l}\text { Spesifikasi dan Nameplate kWh Meter Sigma } \\
\text { Electric }\end{array}$} \\
\hline Tipe kWh Meter & SE 88 A3 \\
\hline Pengawatan & $\begin{array}{c}\text { Fasa Tunggal } 2 \\
\text { Kawat }\end{array}$ \\
\hline Tegangan & 230 Volt \\
\hline Frekuensi & $50 \mathrm{~Hz}$ \\
\hline Konstanta & 900 Putaran/kWh \\
\hline Kelas kWh Meter & Kelas 2 \\
\hline $\begin{array}{c}\text { Batas Pengukuran kWh } \\
\text { Meter }\end{array}$ & $5(20) \mathrm{A}$ \\
\hline Tahun kWh Meter & 1996 \\
\hline
\end{tabular}

\section{HASIL DAN PEMBAHASAN}

a) Pengujian Teknis

- Daya yang Terukur Melewati kWh Meter Melcoinda

$$
\begin{aligned}
& \mathrm{P} 1 \frac{3600 \times \mathrm{n}}{\overline{\mathrm{t}} \times \mathrm{C}} \\
& \mathrm{P} 1=\frac{3600 \times 3}{6,39 \times 900} \\
& \mathrm{P} 1=1,88 \mathrm{~kW}
\end{aligned}
$$


- Daya Aktif yang Diukur Melalui Tang

$$
\begin{aligned}
& \mathrm{kW} \text { P2 } \quad=\mathrm{V} \times \mathrm{I} \times \operatorname{Cos} \varphi \\
& \mathrm{P} 2 \quad=220 \times 10 \times 0,85 \\
& \mathrm{P} 2=1,87 \mathrm{~kW}
\end{aligned}
$$

- Kesalahan kWh Meter Melcoinda (Error \%)

$$
\begin{aligned}
\text { Error }(\%) & =\frac{\mathrm{P} 1-\mathrm{P} 2}{\mathrm{P} 2} \times 100 \% \\
\text { Error }(\%) & =\frac{1,88-1,87}{1.87} \times 100 \% \\
\text { Error }(\%) & =\frac{0,01}{1,87} \times 100 \% \\
\text { Error }(\%) & =0,42 \%
\end{aligned}
$$

Pada hasil pengujian seperti ini, kecepatan putar pada piringan aluminium sebanding dengan daya listrik yang dikonsumsi (Kecepatan Piringan Putar = Daya Listrik yang Dikonsumsi).

- Daya yang Terukur Melewati kWh Meter Fuji Dharma Electric

$$
\begin{aligned}
& \mathrm{P} 1=\frac{3600 \times \mathrm{n}}{\mathrm{t} \times \mathrm{c}} \\
& \mathrm{P} 1=\frac{3600 \times 3}{6,07 \times 900} \\
& \mathrm{P} 1=1,97 \mathrm{~kW}
\end{aligned}
$$

- Daya Aktif yang Diukur Melalui Tang

$$
\begin{aligned}
& \mathrm{kWP2} \quad=\mathrm{V} \times \mathrm{I} \times \operatorname{Cos} \varphi \\
& \text { P2 } \quad=220 \times 10 \times 0,85 \\
& \mathrm{P2}=1,87 \mathrm{~kW}
\end{aligned}
$$

- Kesalahan kWh Meter Fuji Dharma Electric (Error \%)

$$
\begin{array}{ll}
\operatorname{Error}(\%) & =\frac{\mathrm{P} 1-\mathrm{P} 2}{\mathrm{P} 2} \times 100 \% \\
\operatorname{Error}(\%) & =\frac{1,976-1,87}{1.87} \times 100 \% \\
\operatorname{Error}(\%) & =\frac{0,10}{1,87} \times 100 \% \\
\operatorname{Error}(\%) & =5,71 \%
\end{array}
$$

Pada hasil pengujian seperti ini, kWh Meter mengalami abnormal dimana pada kecepatan putar pada piringan aluminium tidak sebanding dengan daya listrik yang dikonsumsi (Kecepatan Putar Piringan > Daya Listrik yang Dikonsumsi). 
- Daya yang Terukur Melewati kWh Meter Sigma Electric

$$
\begin{aligned}
& \mathrm{P} 1=\frac{3600 \times \mathrm{n}}{\mathrm{t} \times \mathrm{c}} \\
& \mathrm{P} 1=\frac{3600 \times 3}{7,92 \times 900} \\
& \mathrm{P} 1=1,51 \mathrm{~kW}
\end{aligned}
$$

- Daya Aktif yang Diukur Melalui Tang

$$
\begin{aligned}
& \mathrm{kWP2}=\mathrm{V} \times \mathrm{I} \times \operatorname{Cos} \varphi \\
& \mathrm{P} 2 \quad=220 \times 10 \times 0,85 \\
& \text { P2 }=1,87 \mathrm{~kW}
\end{aligned}
$$

- Kesalahan kWh Meter Sigma Electric (Error \%)

$$
\begin{array}{ll}
\operatorname{Error}(\%) & =\frac{\mathrm{P} 1-\mathrm{P} 2}{\mathrm{P} 2} \times 100 \% \\
\operatorname{Error}(\%) & =\frac{1,51-1,87}{1,87} \times 100 \% \\
\operatorname{Error}(\%) & =\frac{-0,354}{1,87} \times 100 \% \\
\text { Error }(\%) & =-18,97 \%
\end{array}
$$

Pada hasil pengujian seperti ini, kWh Meter mengalami abnormal dimana pada kecepatan putar pada piringan aluminium tidak sebanding dengan daya listrik yang dikonsumsi (Kecepatan Putar Piringan < Daya Listrik yang Dikonsumsi).

(b)Pengujian Non Teknis

- Penentuan kWh Meter Non Teknis Golongan I (P1)

Pelanggaran Golongan I (P1) adalah pelanggaran yang dapat mempengaruhi pembatas daya tetapi tidak mempengaruhi daripada pengukuran energi.

- Penentuan kWh Meter Non Teknis Golongan II (P2)

Pelanggaran Golongan II (P2) adalah pelanggaran yang dapat mempengaruhi daripada pengukuran energi listrik, tetapi tidak dapat mempengaruhi pembatas daya nya. Pada kasus tersebut, hal ini tentu dapat menyebabkan losses yang dapat terbilang cukup besar, karena menurut studi penulis, dengan adanya kejadian seperti kasus diatas hal ini dapat menyebabkan deviasi kWh Meter minus (-), dikisaran $-35 \%$ sampai dengan $-70 \%$ (Besarnya Minus (-) dapat dipengaruhi oleh semakin besarnya luas penampang pada lempengan tembaga yang digunakan).

- Penentuan kWh Meter Non Teknis Golongan III (P3)

Pelanggaran Golongan III (P3) adalah pelanggaran yang dapat mempengaruhi pembatas daya dan juga dapat mempengaruhi daripada pengukuran energi listrik.

- Kabel Sambung Langsung

Kabel Sambung Langsung, hal ini tentu dapat menyebabkan losses yang dapat terbilang pelanggaran yang sangat besar, dikarenakan dengan adanya 
kejadian seperti kasus diatas hal ini dapat menyebabkan deviasi kWh Meter minus (-) - $100 \%$, dikarenakan komponen yang di connect kan tidak akan terukur oleh kWh Meter, sehingga hal ini dapat menyebabkan losses yang sangat besar sekali dan tentunya dapat merugikan perusahaan.

Dari hasil pengujian secara Teknis terhadap $3 \mathrm{kWh}$ Meter yang dimana didapatkan data dan spesifikasi hingga deviasi kWh Meter, yaitu pada kWh Meter tipe Melcoinda didapatkan deviasi kWh Meter sebesar 1,216282325950168 \%, hal ini terbilang cukup baik dari segi pengukuran dikarenakan sudah sesuai dengan aturan yang telah ditetapkan oleh SPLN. Berikutnya ada kWh Meter merk Fuji Dharma Electric didapatkan deviasi kWh Meter sebesar $5,718489282788149 \%$, hal ini bisa dibilang baik bagi perushaan, karena menguntungkan PLN sekitar 3,718489282788149\% dari pembayaran yang dilakuakan oleh konsumen PLN dan begitu juga sebaliknya hal ini merugikan Konsumen PLN tetapi hanya dalam skala yang kecil.

Berikutnya ada kWh Meter merk Sigma Electric dimana pada kWh meter ini didapatkan deviasi kWh Meter sebesar $-18,97585480473181 \%$, hal ini tentu sangat merugikan PLN, dikarenakan PLN losses sebesar -16,97585480473181\% pada pemakaian kWh Meter merk Sigma Electric, dan ini tentu sangat jauh sekali dari aturan yang telah ditetapkan oleh SPLN. Berikutnya dari hasil studi yang dilakukan terhadap pengujian secara Non Teknis, tenyata hal inilah yang menyumbang losses dalam skala yang besar, dikarenakan pada kasus ini dapat menyumbang losses pada deviasi kWh minus sekitar $-35 \%$ sampai $-70 \%$, hingga kasus yang paling parah ialah dapat menyumbang losses pada deviasi kWh sebesar $-100 \%$.

\section{KESIMPULAN DAN SARAN}

\subsection{Kesimpulan}

Dari hasil pengujian secara Teknis terhadap $3 \mathrm{kWh}$ Meter yang dimana didapatkan data dan spesifikasi hingga deviasi kWh Meter, bahwasannya kWh Meter bertipe ke 3 tesebut didapatkan deviasi kWh sebesar: Melcoinda $=1,216282325950168 \%$ (Layak), dikarenakan pada kondisi seperti ini, kecepatan putar pada piringan aluminium sebanding dengan daya listrik yang dikonsumsi (Kecepatan Piringan Putar = Daya Listrik yang Dikonsumsi). Fuji Dharma Electric $=5,718489282788149 \%$ (Merugikan Konsumen), dikarenakan pada kondisi seperti ini, kWh Meter mengalami abnormal dimana pada kecepatan putar pada piringan aluminium tidak sebanding dengan daya listrik yang dikonsumsi (Kecepatan Putar Piringan $>$ Daya Listrik yang Dikonsumsi). Sigma Electric = $-18,97585480473181 \%$ (Merugikan Perusahaan), dikarenakan pada kondisi seperti ini, kWh Meter mengalami abnormal dimana pada kecepatan putar pada piringan aluminium tidak sebanding dengan daya listrik yang dikonsumsi (Kecepatan Putar Piringan < Daya Listrik yang Dikonsumsi).

\subsection{Saran}

Dari hasil pengujian secara Teknis yang telah dilakukan, sebaiknya kWh Meter yang memiliki pengukuran deviasi kWh Meter yang buruk, harap dapat diperbarui dengan kWh Meter yang lebih baik, contoh seperti kWh Meter Melcoinda, sehingga pada hal ini dapat menekan losses menjadi lebih kecil/rendah lagi. 
UCAPAN TERIMAKASIH

Penulis mengucapkan terima kasih kepada Institut Teknologi PLN, Jakarta, Indonesia yang telah memberi dukungan yang membantu pelaksanaan penelitian dan penulisan artikel ilmiah ini.

\section{DAFTAR PUSTAKA}

[1] Alfarizi, L. D. (2020). Studi Perbandingan Pembacaan Meteran Pada Kwh Meter PLN Dengan Kwh Meter Tide, Co Di Area Pt Pln (Persero) Up3 Cengkareng.

[2] Asrul, J., \& Firmansyah, F. (2014). Reconnecting Sambungan Rumah (Sr) Pada Gardu 079 Sovia Untuk Mengurangi Losses Di PT PLN (Persero) Rayon Bukittinggi (Menggunakan Aplikasi Jaringan Syaraf Tiruan). Elektron: Jurnal IImiah, 6(1), 1627. https://doi.org/10.30630/eji.6.1.61

[3] Darma, S. (2019). Studi sistem peneraan kwh meter. Journal of Electrical Technology, 4(3), 158-165.

[4] Gunawan, D., Erwanto, D., \& Shalahuddin, Y. (2018). Studi Komparasi Kwh Meter Pascabayar Dengan Kwh Meter Prabayar Tentang Akurasi Pengukuran Terhadap Tarif Listrik Yang Bervariasi. Setrum: Sistem Kendali-Tenaga-ElektronikaTelekomunikasi-Komputer, 7(1), 158. https://doi.org/10.36055/setrum.v7i1.3408

[5] Mohamad Andri Wijaya Taqijuddin.A, \& Bambang Dwi Sulo. (2019). Sistem Monitoring Kwh Meter Berbasis Internet Guna Memonitoring Rugi Daya Dan Tegangan Jatuh Pada Penyulang Kalipare. 53(9), 1-9.

[6] Mungkin, M., Satria, H., Bahri, Z., \& Ridwan, A. (2020). Pengujian Keandalan Sistem Current Transformer Dalam Menanggulangi Penggunaan Energi Listrik Secara llegal. 7(2), 99-107.

[7] Samsurizal, Faber Agustinus G Siagian, Andi Makkulau (2021). Kajian Dampak Ketidaknormalan Meter Elektronik Pada Sistem Automatic Meter Reading Pada Pelanggan Tegangan Rendah. Jurnal Elektroda 6(2), 105-108

[8] S, D. W., \& Suyaningsih, N. (2018). Deteksi Pemakaian Tenaga Listrik Terhadap Deviasi kWh Meter Berbasis Mikrokontroller. Semrestek 2018, 391-405.

[9] Wiharja, U. (2017). Analisa Deteksi Ketidaknormalan Meter Elektronik Dengan Sistem Automatic Meter Reading. Jurnal IImiah Elektrokrisna, 6(1), 89-96. 